\title{
111. Duplication of Sexual Organs in the Male-Moth of Bombyx mori $L$.
}

\author{
By Yositiro UMEYA.
}

(Comm. by C. IshikAwA, M.I.A., Nov. 12, 1930.)

Introduction. $\mathrm{My}$ former investigations ${ }^{1,2), 3)}$ on the degenerated motor muscles of penes in the Japanese bivoltine race were restricted to the external features only, since the internal organs were found to be all normal. Four specimens were found this year in which the internal organs were also duplicated. The internal sexual organs, with the exception of vas deferens and testes, show the same duplication as the external organs. As far as I know the occurrence of such a duplication of the sexual organs in an individual which is not a gynander is not as yet on record.

The aim of the present investigation is to describe the states of the duplication of these organs, but may also be of interest in giving us some hint as to the formation of sexual organs in insects.

The expense of the present study has partly been defrayed by the grant given by the Imperial Academy.

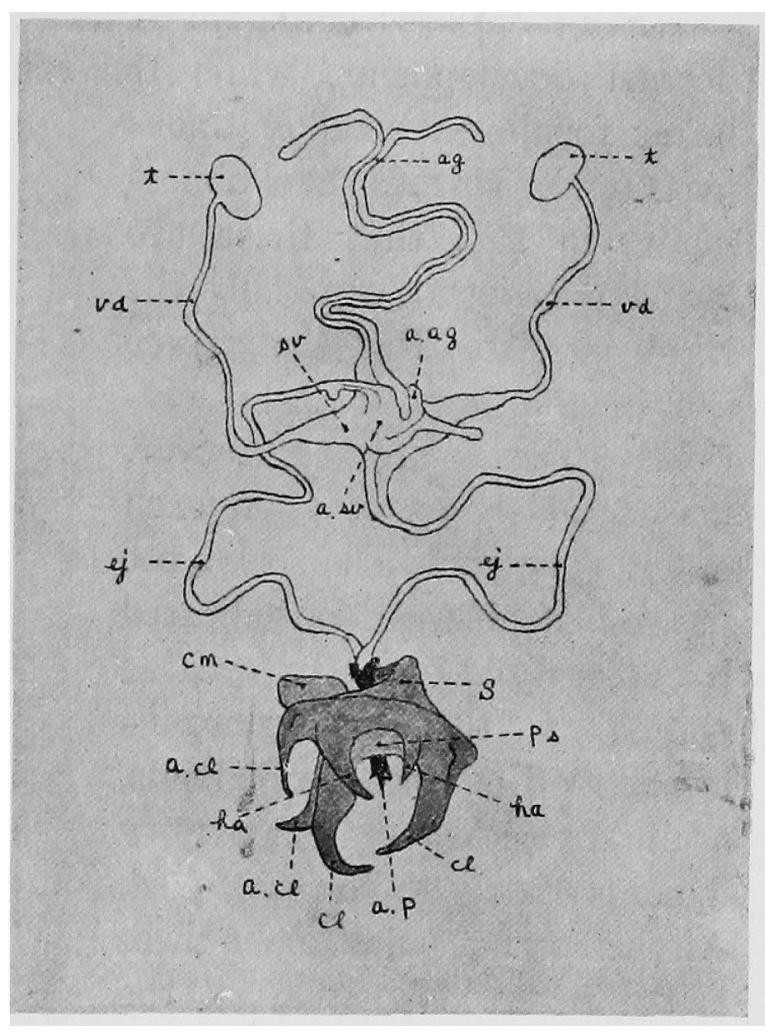

Fig. 1.

Duplication of sexual organs of male-moth. First example. Of the internal organs: $t$, testes ; $v d$, vas deferens; $a g$, accessory glands; aag, abnormal accessory glands; $s v$, seminal vesicles; asv, abnormal seminal vesicles; $e j$, ejaclatory ducts. Of the external organs: $a p$, abnormal penis; $h a$, harpes; $p s$, penis sheath; $c l$, clasper; $a c l$, abnormal clasper; $c m$, abnormal basis of clasper; $s$, saccus.

1) Jour. Call. Agrie. Imp. Univ. Tokyo, Vol. IX, No. 1, 1925.

2) Proc., 6 (1930).

3) Jour. Nat. Hist. Soci. Chosen, No. 9 (in Japanese), 1929. 
Morphology of the duplicate sexual organs. In all the examples the external sexual organs consist of, as already described, two pairs of claspers, of harpes, and of penes with chitinous sheaths. Of the internal organs two pairs of accessory glands, of seminal vesicles, and of ejaculatory ducts are found to be present. On the other hand, succus (sternum of the 9 th abdominal segment), diagonal piece (tergum of the same), uncus (sternum of the 10th segment), and scaphium (tergum of the same) in the external organs, and vas deferens and testes in the internal organs are normal.

First example (Fig. 1):-One of the two pairs of claspers show normal development, while the other is malformed, the basis of the latter forming a small chitinous mass $(\mathrm{cm})$. Harpes show abnormality in this that these are larger than usual, especially the right one, showing that these are in the process of bifurcation. These are, moreover, placed widely apart from each other. The penis also shows the process of bifurcation, indicated by its base and by its trifurcated points. In the internal organs duplication of accessory glands, seminal vesicles, and ejaculatory ducts is clearly to be recognized. An interesting point about these is the reversed position of the duplicated organs, as given in Figs. 1 and 2 (in these figures scaphium and uncus protecting the anus are not given).

Second example (Fig. 2) :The external appearance of this moth shows no sign of duplication, but a dissection of the animal reveals the presence of a large chitinous mass with an abnormally curved penis lying free in the body cavity, thus

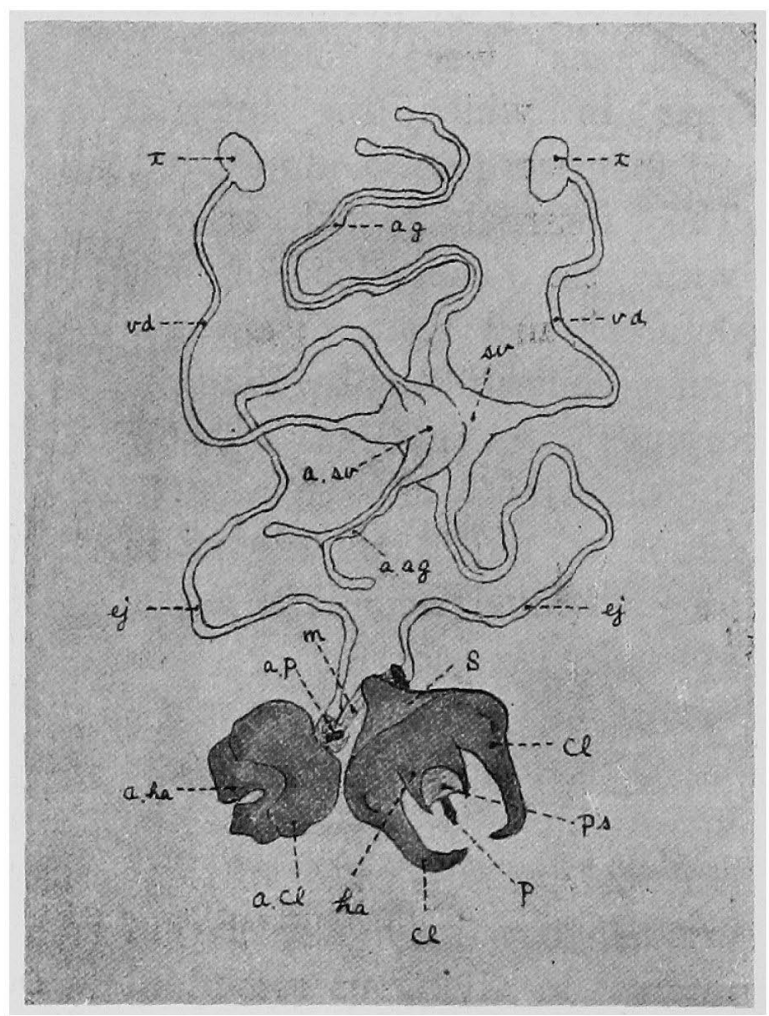

Fig. 2.

Duplication of sexual organs. Second example. Of the internal organs: $t$, testes; $v d$, vas deferens; $a g$, accessory glands; $a a g$, abnormal accessory glands; $s v$, seminal vesicles; asv, abnormal seminal vesicles; $e j$, ejaculatory ducts. Of the external organs: $p$, penis; $a p$, abnormal penis; $p s$, penis sheath; $s$, saccus; $m$, motor muscles; $c l$, clasper; $a c l$, abnormal clasper; $h a$, harpes; aha. abnormal harpes. 
showing the duplication of the external organs. The mass consists of abnormal claspers and harpes.

Of the internal organs two ejaculatory ducts are normal, while two pairs of accessory glands and seminal vesicles are abnormal and placed in reversed position just as in the first example.

The conditions found in the third and the fourth examples are on the whole similar to those of the second, so that the description of these two will not be given.

In all the examples tetes and vas deference are normal, showing no duplication. The moth of the first example can not copulate at all, while those of the other three may possibly do so, since the organs lying outside of the body show no abnormal development. It is also to be stated that the external appearance of the moths of the other three is quite normal, in spite of the presence of duplicate organs within the body cavity.

As previously reported by Nussbaum ${ }^{1)}$ and the present writer both the external (claspers, harpes, penis and its sheath) and the internal organs (seminal vesicles, accessory glands and ejaculatory

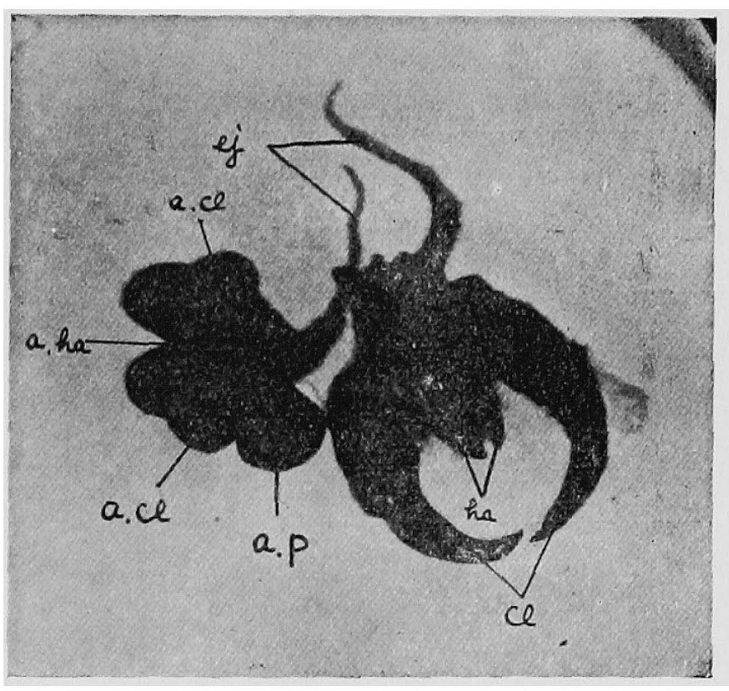

Fig. 3.

Duplication of external genital organs, another example. $e j$, ejaculatory ducts; $c l$, clasper; $a c l$, abnormal clasper; $h a$, harpes; $a h a$, abnormal harpes; ap abnormal penis. ducts) are formed from the ectoderm of Herold's organ, the fact which shows that these male organs are developed from the same germinal layer as those of the female, namely from the ectoderm. This is not in accordance with the statement of Verson $u$. Bisson ${ }^{2)}$ according to which not only vas deferens and testes are developed from the mesoderm, but the internal accessory organs are also derived from the same layer. From all these we may arrive at the conclusion that the abnormalities above described must have originated from the doubling of the imaginal discs.

1) Zool. Anzeiger, Bd. 5, 1882.

2) Zeitsch. f. wiss. Zool., Bd. 61, 1896. 
The cause of the abnormalities is not, however, clear; but judging from the fact that the moths have arisen from a strain belonging to the pedigree of the abnormal male having the hereditary trait of genitalia as previously described, it is very probable that the malformation is due to a mutation.

But whether the character is truly hereditary or not can only be ascertained by crossing experiments. 